\title{
Correlation Between Nutrition Status and Lipid Profile Toward Sexual Satisfaction on Perimenopause Women in Working Area Public Health Centre (PHC) of Bara-Baraya
}

\author{
Jumrah ${ }^{*}$, Rosdianah1, Syamsuriyana Sabar ${ }^{2}$, Ayu Lestari2 ${ }^{2}$ Julia Fitria Ningsih ${ }^{2}$ \\ 1) Midwifery Study Program, Mega Rezky Kwolegde of Health Sciences, Makassar, Indonesia \\ 2) Department of Nursing, Mega Rezky Kwolegde of Health Sciences, Makassar, Indonesia \\ jumrah.mega.rezky@gmail.com
}

DOI: http://doi.org/10.29080/jhsp.v3i3S.276

\section{Keywords}

Sexual

satisfaction;

Nutritional

status;

Lipid profile.

\begin{abstract}
Premenopausal woman is a physiological state that has entered the aging process, which is characterized by decreased ovarian estrogen production. In conditions of estrogen deficiency often arise various debilitating syndrome called premenopausal syndrome women. This study aims to determine the relationship of nutritional status and lipid profile to sexual satisfaction in perimenopausal women. This study used cross-sectional study. The sample in this study is partly perimenopausal women in Puskesmas Bara-baraya total of 37 respondents. Data analysis used chi-square test with $\alpha=0.05$. It is shown that there was no relationship always connects two things of nutritional status based on BMI $(\rho=0.347)$.However, the relationship is shown based on the circumference of the abdomen showed a link $(\rho=0.048)$. Based on cholesterol for the status of lipid, it is shown that there is no association with sexual satisfaction ( $\rho$ $=0.006)$, while based triglycerides, it showed no correlation as well $(\rho=0.571)$.
\end{abstract}

\section{Introduction}

Premenopausal is a phase in the aging process, in which a woman experiences a transition from reproductive to non-reproductive period. This period is marked by the physiological state of women entering the aging process where the production of estrogen hormone decreases. Several symptoms characterized this condition that indicate that a woman has entered the premenopausal period. Symptoms of premenopausal consist of physical changes and mental changes. This set of symptoms can cause a syndrome that greatly disrupts a woman's activity called premenopausal syndrome (1).

Epidemiologically, the syndrome is experienced by many women in the entire world, accounting for around $70-80 \%$ in Europe, $60 \%$ in America, $57 \%$ in Malaysia, $18 \%$ in China, and $10 \%$ in Japan and Indonesia. Some of the data collected revealed that one of the factors that causes the difference in number is diet. European and American women have more estrogen than Asian women. When menopause occurs, European and American women experience a drastic decrease in estrogen compared to Asian women. This will affect the life expectancy at birth (2).

Data obtained from the office of demographic affairs of Makassar [2015] showed that the population of women aged 25-35 years old is 48,984, women aged 40-50 years old amount to 80,228, and women over 50 years old are 693,423. Moreover, data obtained from the Bara-Baraya Health Center revealed that in 2013 , the total population of women aged 20-39 years old was 7,113, women aged 40-49 years old were 1,829 , and women over 50 years old were 2,564 , whereas in 2014 , the population of women aged 20-39 years old was 7,336, women aged 40-49 years old were 1883, and women aged over 50 years old were $2,564(3)$.

Along with the increase of life expectancy at birth, it is predicted that in 2020 there will be an increase in the number and proportion of the population of women over 50 years old with a total of $29,872,900$ or $11.42 \%$ of the total population of Indonesia. In this group age, women experience 
menopause which can disturb their activities and reduce their quality of life. In fact, when entering the age of 40 years old, women often experience anovulation menstruation related to ovarian function. Therefore, special attention is needed so that women in this group of age can still be productive and their sexual lives are maintained (4).

Sexuality is part of human life, so the quality of sexual life determines the quality of life [Azizah, 2011]. Sexual dysfunction is one of the problems that can occur in the elderly. Sexual dysfunction includes vaginal lubrication disorders, the lack of interest in sexual relations, dyspareunia, difficulty in reaching orgasm, and unpleasant feeling about sex (5).

During perimenopause, there is a decrease in the hormone estrogen and an increase in the hormone gonadropin. With the reduction of estrogen in the body, the function of the related organs changes. In the perimenopause period, women's health status becomes worse. This will affect the quality of life (QOL) of women in perimenopause (6).

The decrease in estrogen, progesterone, and testosterone greatly affects women's sexual function. With reduced estrogen can cause loss of lubrication of the vagina, and the vagina will thin and shorten. Where this will cause dyspareunia. For women who regularly have sexual intercourse, this symptom will decrease. If the conditions are not treated, it will cause itching and heat in the vulva and vagina, infection of the urinary tract (caused by an increase in vaginal pH that causes the development of coliform bacteria), and incontinence uri (stress incontinence and continence). Therefore, the researcher decided to examine the effect of nutritional status and lipid profile on sexual.

\section{Methods}

\section{Research Location and Design}

This research was carried out at Bara-Baraya Health Center in Makassar. The type of this research is cross-sectional study.

\section{Population and Sample}

The population of this study was 60 premenopausal women who were not exposed to hormonal contraception at the working area of Bara-Baraya Health Center in Makassar where 37 of them, who met the inclusion criteria such as Women in perimenopausal age-aged 42-50 years, willing to be research subjects, women who have husbands, age of husbands $<65$ years, has no disease, never use hormonal contraception and blood sugar $<200 \mathrm{mg} / \mathrm{dl}$, were taken as samples using purposive sampling technique.

\section{Data Collection}

The of research data was primary data. Measurement of nutritional status was carried out using weight scale, meter band, and height measurement device. Nutritional status is calculated based on body mass index (BMI) and abdominal circumference. BMI measured by weight in kilograms (kg) with height in units of squared meters $(\mathrm{m} 2)$. Abdominal circumference is measured in centimeters $(\mathrm{cm})$. With the midpoint of the tip of the spine/ hip. Nutritional status criteria are determined to be normal or obesity. The measurement is done by the researchers themselves. Measurement of lipid profile is calculated by measuring the patient's cholesterol and triglyceride levels. Measuring by taking blood specimens which are then examined in the laboratory. The criteria for lipid profiles are carried out at normal levels or high. Measurement of sexual satisfaction was through plural using questionnaires of the Female Sexual Function Index (FSFI). This questionnaire has been tested for validity and purpose in previous studies. This questionnaire consists of 19 items that have demonstrated reliability, good validity, and most importantly have been shown to have a sensitivity of $89.9 \%$ and a specificity of $86.3 \%$ (7). Sexual Satisfaction is categorized as satisfied and dissatisfied.

Data Analysis

The technique of data analysis used was a univariate analysis which aimed to see the description of the frequency distribution of respondents' characteristics. The bivariate analysis aimed to see the effect of independent variables on the dependent variable using the Chi-Square test. Multivariate analysis was conducted to see the extent of the influence of each independent variable, which in this case was nutritional status and lipid profile, on the dependent variable, which in this case was sexual satisfaction, using multiple logistic regression tests.

\section{Results \\ Univariate Analysis}

Table 1 showed the characteristics of respondents in which of the 37 respondents, 19 (51.35\%) respondents were with parity of $1-3,32(86.49 \%)$ respondents were housewives, and 9 (24.33\%)respondents has been married for 11 to 15 years and more than 20 years. In terms of education level, 23 (62.16\%) respondents graduated from high school, while with respect to job, 35 (94.6\%) respondents worked as entrepreneurs. 
Table 1 The Characteristics of Respondents

\begin{tabular}{|c|c|c|}
\hline Characteristics & (n) & $(\%)$ \\
\hline \multicolumn{3}{|l|}{ Parity } \\
\hline 0 & 10 & 27,03 \\
\hline $1-3$ & 19 & 51,35 \\
\hline$>3$ & 8 & 21,62 \\
\hline \multicolumn{3}{|l|}{ Work } \\
\hline Housewife & 32 & 86,49 \\
\hline Government employees & 4 & 10,81 \\
\hline entrepreneur & 1 & 2,70 \\
\hline \multicolumn{3}{|l|}{ Long Married } \\
\hline$<6$ years & 8 & 21,62 \\
\hline $6-10$ years & 3 & 8,1 \\
\hline $11-15$ years & 9 & 24,33 \\
\hline $16-20$ years & 8 & 21,62 \\
\hline$>20$ years & 9 & 24,33 \\
\hline Level of education & & 1892 \\
\hline Elementary school & 7 & 18,92 \\
\hline Middle school & 6 & 16,22 \\
\hline High school & 23 & 62,16 \\
\hline Diploma & 1 & 2,7 \\
\hline \multicolumn{3}{|l|}{ Husband's work } \\
\hline entrepreneur & 35 & 27 \\
\hline Government employees & 1 & 2,1 \\
\hline Does not work & 1 & 2,7 \\
\hline Total & 37 & 100 \\
\hline
\end{tabular}

Source: Primary Data of the 2016 PKM Bara-Baraya Makassar

Table 2 showed the characteristics of respondents based on the variables studied. This table revealed that out of 37 respondents, 20 (54.1\%) respondents had good sexual satisfaction, 17 (46\%) respondents had a Normal BMI, and 24 (64.9\%) respondents were obese with an abdominal circumference of more than $80 \mathrm{~cm}$. For lipid profile, $23(62.2 \%)$ respondents had normal cholesterol level of less than $200 \mathrm{kcal}$, and 21 $(56.8 \%)$ respondents with a high level of triglycerides $(\geq 150 \mathrm{mg} / \mathrm{dl})$. 
Table 2 the characteristics of respondents based on the variables studied (Nutrition status, Lipid Profile, and sexual satisfaction)

\begin{tabular}{lcc}
\multicolumn{1}{c}{ Variable } & $\mathrm{n}$ & Percentage (\%) \\
\hline sexual satisfaction & 20 & 54,1 \\
Satisfied & 17 & 45,9 \\
Not satisfied & & \\
Nutrition status & & \\
BMI & 16 & 43,2 \\
$\quad$ Normal & 21 & 56,8 \\
$\quad$ Obesity & & \\
Stomach Circumference & & \\
$\quad$ Normal $(\leq 80 \mathrm{~cm})$ & 13 & 35,1 \\
Obesity $(>80 \mathrm{~cm})$ & 24 & 64,9 \\
& & \\
Lipid profile & & 62,2 \\
Cholesterol & 23 & 37,8 \\
Normal (<200 mg / dl) & 14 & \\
High ( $\geq 200 \mathrm{mg} / \mathrm{dl})$ & & 43,2 \\
$\quad$ Triglycerides & 16 & 56,8 \\
Normal (<150 mg / dl) & 21 & \\
High ( $\geq 150 \mathrm{mg} / \mathrm{dl})$ & & 100 \\
\hline$\quad$ Total & 37 & \\
\hline
\end{tabular}

Source: Primary Data of the 2016 PKM Bara-Baraya Makassar

\section{Bivariate Analysis}

Table 3 showed the nutritional status of respondents with the indicator of BMI and Stomach Circular on triglycerides. The result of chi-square statistical test for BMI with triglycerides indicated that the value of $\rho(0.697>\alpha(0.05)$ which meant that there was no correlation between the Body Mass Index and triglycerides in premenopausal women, while for the abdominal circumference, the value of $\rho(0.045)<\alpha$ $(0.05)$ which meant that there was a correlation between abdominal circumference and triglycerides.

Table 3 The nutritional status of respondents with the indicator of BMI and Stomach Circular on triglycerides

\begin{tabular}{|c|c|c|c|c|c|c|c|}
\hline \multirow{3}{*}{ The nutritional status } & \multicolumn{4}{|c|}{ Trigliserida } & \multirow{2}{*}{\multicolumn{2}{|c|}{ Total }} & \multirow{3}{*}{ Nilai $\rho$} \\
\hline & \multicolumn{2}{|c|}{ Normal } & \multicolumn{2}{|c|}{ High } & & & \\
\hline & $\mathrm{n}$ & $\%$ & $\mathrm{n}$ & $\%$ & $\mathrm{~N}$ & $\%$ & \\
\hline \multicolumn{8}{|l|}{ BMI } \\
\hline Normal & 8 & 50,0 & 8 & 50,0 & 16 & 100 & 0,697 \\
\hline Obesity & 8 & 38,1 & 13 & 61,9 & 21 & 100 & \\
\hline \multicolumn{8}{|l|}{ Stomach Circular } \\
\hline Normal & 9 & 69,2 & 4 & 30,8 & 13 & 100 & 0,045 \\
\hline Obesitas & 7 & 29,2 & 17 & 70,8 & 24 & 100 & \\
\hline Total & 16 & 43,2 & 21 & 56,8 & 37 & 100 & \\
\hline
\end{tabular}

Source: Primary Data of the 2016 PKM Bara-Baraya Makassar

Table 4 showed the nutritional status of respondents with the indicator of BMI and Stomach Circumference on total cholesterol. The result of the chi-square statistical test for BMI with cholesterol indicated that the value of $\rho(0.179)>\alpha(0.05)$ which meant that there was no correlation between the Body Mass Index and cholesterol in premenopausal women, while for the abdominal circumference, the value $\rho$ $(0.042)<\alpha(0.05)$ which meant that there was a correlation between abdominal circumference and cholesterolin premenopausal women. 
Table 4 the nutritional status of respondents with the indicator of BMI and Stomach Circumference on total cholesterol

\begin{tabular}{|c|c|c|c|c|c|c|c|}
\hline \multirow{3}{*}{ the nutritional status } & \multicolumn{4}{|c|}{ Cholesterol } & \multirow{2}{*}{\multicolumn{2}{|c|}{ Total }} & \multirow{3}{*}{ Nilai $\rho$} \\
\hline & \multicolumn{2}{|c|}{ Normal } & \multicolumn{2}{|c|}{ High } & & & \\
\hline & $\mathrm{n}$ & $\%$ & $\mathrm{n}$ & $\%$ & $\mathrm{~N}$ & $\%$ & \\
\hline \multicolumn{8}{|l|}{ BMI } \\
\hline Normal & 12 & 75,0 & 4 & 25,0 & 16 & 100 & 0,179 \\
\hline Obesity & 10 & 76,5 & 11 & 23,5 & 21 & 100 & \\
\hline \multicolumn{8}{|l|}{ Stomach Circular } \\
\hline Normal & 11 & 84,6 & 2 & 15,4 & 13 & 100 & 0,042 \\
\hline Obesitas & 11 & 45,8 & 13 & 54,2 & 24 & 100 & \\
\hline Total & 22 & 59,5 & 15 & 40,5 & 37 & 100 & \\
\hline
\end{tabular}

Source: Primary Data of the 2016 PKM Bara-Baraya

Table 5 showed that out of 16 respondents who had a normal BMI, 9 respondents (56.2\%) were sexually satisfied and 7 respondents (43.8\%) were sexually dissatisfied. Out of 21 respondents who had BMI in the fat category, 11 respondents (52.4\%) were sexually satisfied and 10 respondents (47.6\%)were sexually dissatisfied. The chi-square statistical test result revealed that the value is $\rho(1,000)>\alpha(0.05)$, meaning that there was no correlation between the Body Mass Index and the sexual satisfaction of premenopausal women.

Table 5 Corelation between Nutritional Status and Sexual Satisfaction

\begin{tabular}{|c|c|c|c|c|c|c|c|}
\hline \multirow{3}{*}{ Nutritional Status } & \multicolumn{4}{|c|}{ Sexual Satisfaction } & \multirow{2}{*}{\multicolumn{2}{|c|}{ Total }} & \multirow{3}{*}{ Nilai $\rho$} \\
\hline & \multicolumn{2}{|c|}{ Satisfaction } & \multicolumn{2}{|c|}{ Not Satisfaction } & & & \\
\hline & $\mathrm{n}$ & $\%$ & $\mathrm{n}$ & $\%$ & $\mathrm{~N}$ & $\%$ & \\
\hline \multicolumn{8}{|l|}{ BMI } \\
\hline Normal & 9 & 56,2 & 7 & 43,8 & 16 & 100 & 1,000 \\
\hline Obesity & 11 & 52,4 & 10 & 47,6 & 21 & 100 & \\
\hline \multicolumn{8}{|l|}{ Stomach Circular } \\
\hline Normal & 10 & 76,9 & 3 & 23,1 & 13 & 100 & 0,048 \\
\hline Obesitas & 10 & 41,7 & 14 & 58,3 & 24 & 100 & \\
\hline Total & 20 & 54,1 & 17 & 45,9 & 37 & 100 & \\
\hline
\end{tabular}

Moreover, out of 13 respondents who had the abdominal circumference, 10 respondents (76.9\%) were sexually satisfied and 3 respondents (23.1\%) were sexually dissatisfied. Out of 24 respondents who had abdominal circumference the obesity category, 10 respondents (41.7\%) were sexually satisfied and 14 respondents $(58.3 \%)$ were sexually dissatisfied. The result of chi square statistical test indicated that the value is $\rho(0.048)<\alpha(0.05)$, meaning that there was a correlation between abdominal circumference and sexual satisfaction of premenopausal women.

Table 6 showed that out of 23 respondents who had normal cholesterol $(<200 \mathrm{mg} / \mathrm{dl}), 17$ respondents (73.9\%) were sexually satisfied and 6 respondents $(26.1 \%)$ were sexually dissatisfied. Out of 14 respondents who had high cholesterol ( $\geq 200 \mathrm{mg} / \mathrm{dl}), 3$ respondents $(21.4 \%)$ were sexually satisfied and11 respondents (78.6\%) were sexually dissatisfied. The result of chi-square statistical test indicated that the value is $\rho(0.006)<\alpha(0.05)$, showing was a correlation between cholesterol and sexual satisfaction of premenopausal women. 
Table 6 Corelation Lipid Profiles and Sexual Satisfaction

\begin{tabular}{|c|c|c|c|c|c|c|c|}
\hline \multirow{3}{*}{ Lipid Profiles } & \multicolumn{4}{|c|}{ Sexual Satisfaction } & \multirow{2}{*}{\multicolumn{2}{|c|}{ Total }} & \multirow[t]{3}{*}{ Nilai $\rho$} \\
\hline & \multicolumn{2}{|c|}{ Satisfaction } & \multicolumn{2}{|c|}{ Not Satisfaction } & & & \\
\hline & $\mathrm{n}$ & $\%$ & $\mathrm{n}$ & $\%$ & $\mathrm{~N}$ & $\%$ & \\
\hline \multicolumn{8}{|l|}{ Cholesterol } \\
\hline & 17 & 73,9 & 6 & 26,1 & 23 & 100 & 0,006 \\
\hline Normal $(<200 \mathrm{mg} / \mathrm{dl})$ & 3 & 21,4 & 11 & 78,6 & 14 & 100 & \\
\hline \multicolumn{8}{|l|}{ High ( $\geq 200 \mathrm{mg} / \mathrm{dl}$ ) } \\
\hline \multirow[t]{2}{*}{ Triglycerides } & 10 & 62,5 & 6 & 37,5 & 16 & 100 & 0,571 \\
\hline & 10 & 47,6 & 11 & 52,4 & 21 & 100 & \\
\hline Normal (<150 mg / dl) & & & & & & & \\
\hline $\operatorname{High}(\geq 150 \mathrm{mg} / \mathrm{dl})$ & & & & & & & \\
\hline
\end{tabular}

\begin{tabular}{crrrrrr}
\hline Total & 20 & 54,1 & 17 & 45,9 & 37 & 100 \\
\hline
\end{tabular}

Source: Primary Data of the 2016 PKM Bara-Baraya Makassar

Moreover, out of 16 respondents who had normal triglycerides ( $<150 \mathrm{mg} / \mathrm{dl}$ ), who had 10 respondents $(62.5 \%)$ were sexually satisfied and 6 respondents $(37.5 \%)$ were sexually dissatisfied. Out of 21 respondents who had high triglyceride levels ( $\geq 150 \mathrm{mg} / \mathrm{dl}$ ), 10 respondents (47.6\%) were sexually satisfied and 11 respondents (52.4\%)\%)were sexually dissatisfied. The result of chi-square statistical test indicated that the value is $\rho(0.571)>\alpha(0.05)$, indicating was no correlation between triglycerides and sexual satisfaction of premenopausal women.

Table 7 showed that from the variables studied with multiple logistic regression test, the obtained value of $\rho=0.006$ where the value of $\alpha=0.05$. Thus, cholesterol was 16 times the risk of sexual satisfaction, meaning that people with normal cholesterol was 16 times more sexually satisfied than those with high cholesterol.

Table 7. Corelation between Nutritional Status and Lipid Profile with Sexual Satisfaction

\begin{tabular}{lcc}
\hline \multicolumn{1}{c}{ Variabel } & Nilai $\rho$ & OR (exp.B) \\
\hline Nutritional Status & & \\
BMI & 0,111 & 0,119 \\
Stomach Circular & 0,078 & 12,228 \\
& & \\
Lipid Profile & & \\
Cholesterol & 0,006 & 16,307 \\
Triglycerides & 0,234 & 0,228 \\
\hline
\end{tabular}

Source: Primary Data of the 2016 PKM Bara-Baraya Makassar

\section{Discussion}

The purpose of this research was to determine the correlation between nutritional status which is assessed through body Mass Index (BMI), abdominal circumference, and lipid profile based on cholesterol and triglycerides, and sexual satisfaction of premenopausal women. Body mass index (BMI) is one of the calculation indicators to monitor the nutritional status of adults, especially those related to overweight and underweight. The abdominal circumference is the length around the body in a person's abdomen that is parallel to the navel. Measurement of the circumference is done to determine whether there is abdominal or central obesity.

Lipid profile is fat elements in plasma which consists of several elements including cholesterol and triglycerides. Cholesterol is a steroid alcohol, a type of fat found in animal fat, oil, bile, milk, egg yolks, which are mostly synthesized by the liver and a which are a small portion are absorbed through the diet. Triglycerides are energy stores which unit mass is five times more than glycogen. A thin adult has approximately 35 billion adiposities which each contains 0.4-0.6 $\mu$ g of triglycerides. Triglycerides free 9.3 $\mathrm{kcal} / \mathrm{g}$ when oxidized. In comparison, glycogen stored in the liver and muscles produces $4.1 \mathrm{kcal} / \mathrm{g}$ when oxidized. Triglycerides are solidly stored in fat cells (8).

Nutritional status can affect the level of a person's lipid profile. Total cholesterol levels increase in line with an increase in the Body Mass Index. Based on some literature, there is a widespread opinion that a decrease in the Body Mass Index among older people will automatically lead to a decrease in cholesterol levels. Triglycerides are energy stores whose unit mass is five times more than glycogen. A thin adult has approximately 35 billion adiposities which each contain $0.4-0.6 \mu \mathrm{g}$ of triglycerides. 
The results of this study revealed that there was no correlation between BMI and sexual satisfaction of premenopausal women in the working area of Bara-Baraya Health Center. BMI did not show a correlation with sexual satisfaction because nutritional status measured using BMI with indicators of body weight and height was a measure of current nutritional status. Body weight provided a picture of body mass that was very sensitive to sudden changes such as infectious diseases. However, statistically, the number of mothers with a normal BMI who were sexually satisfied was 10 respondents (58.8\%) so that the possibility of a small number of samples could influence the statistical test in this study.

Moreover, this study revealed a significant correlation between the circumference and sexual satisfaction of premenopausal women, as shown in table 5. Measurement of abdominal circumference was done to determine whether there was abdominal or central obesity. This type of obesity is very influential on the occurrence of cardiovascular disease and diabetes mellitus. BMI can assess someone is suffering from obesity or not, while obesity is often accompanied by an increase in total cholesterol and triglyceride levels in the blood

In several studies, it was reported that diabetes mellitus contributed to sexual dysfunction with a prevalence ranging from 20-80\%, while a study conducted in Jordan reported that women aged 50 years or older who suffer from diabetes experience more sexual dysfunction which is in the amount of $5.6 \%$. Sexual problems that can arise due to diabetes include problems with vaginal lubrication and decreased libido (9)

The result of the study on lipid profile variable revealed that there was a correlation between cholesterol and sexual satisfaction of premenopausal women in the working area of Bara-Baraya Health Center $(\rho=0.006)$ while on triglyceride variable, it showed that there was no correlation between cholesterol and sexual satisfaction of premenopausal women in the working area of Bara-Baraya Health Center as shown in table 6.

Multivariate test results showed that the risk factor for cholesterol was 16,307, so it had a 16 times greater risk of sexual satisfaction, meaning that people with normal cholesterol was 16 times more sexually satisfied than those with high cholesterol.

Cholesterol is a precursor to steroid products like sex hormones: estrogen, progesterone, and testosterone. This is in line with research conducted by Jacobsen et al. (2003) that lifestyle with frequent consumption of foods containing fat, can produce higher level of estradiol that circulates in the blood and prolong reproductive function so that estrogen level in the body that stay awake will has an impact on the vaginal state such as maintaining vaginal lubrication and vaginal $\mathrm{pH}$ and affect the libido.Cholesterol is synthesized in the gland or taken from the plasma. Studies of adrenal cells showed that HDL was a plasma component that would give cholesterol to the gland which if not used immediately for the synthesis of steroid hormones, cholesterol will be stored in the gland as a cholesterol ester. Under normal circumstances, about $2 / 3$ of total plasma cholesterol is in the form of an ester. About $60-75 \%$ of cholesterol is transported by LDL, and in a smaller but very significant amount (15-25\%) cholesterol is transported by HDL. Thus, HDL carries excess cholesterol from peripheral (including vascular endothelial cells) back to the liver (10).

In addition, other factors can affect the sexual satisfaction of premenopausal women in the research area, including the husband's job and the food consumption of respondents that have not been controlled in this research. The husband's job can affect the level of sexual satisfaction of women. Jobs with a high level of stress or jobs that make the husband frequently leave the house can affect the sexual satisfaction of respondents in the working area of the Health Center where the research is conducted. Moreover, food consumption can also affect the cholesterol level of respondents.

\section{Conclusion And Recommendation}

Based on the previous result and discussion, it can be concluded that there is a correlation between abdominal circumference and triglycerides and total cholesterol. In central obesity, it is found that dyslipidemia state that describes the excess body fat deposit increase the risk of metabolic syndrome parameter. There was a correlation between the circumference and sexual satisfaction of premenopausal women, while BMI showed that there was no correlation. This occurs because the measurement of the abdominal circumference gives more meaning than BMI in determining fat deposits in the abdominal cavity (central obesity). In this case, an increase in fat deposits in the abdomen is reflected in increased abdominal circumference. In addition, there is a correlation between cholesterol and sexual satisfaction of premenopausal women, while triglycerides have no correlation with the satisfaction of premenopausal women. This happens because cholesterol is an essential component of all cell membranes and is a steroid hormone precursor.

Based on multivariate analysis, only cholesterol showed a correlation with sexual satisfaction. Thus, cholesterol has a 16 times greater risk towards sexual satisfaction, meaning that people with normal cholesterol is 16 times more sexually satisfied than those with high cholesterol. In other words, the more normal cholesterol levels the better sexual satisfaction of a woman. Therefore, health agencies are advised 
to pay more attention to problems in premenopausal women and make them part of public health services. Besides, women are suggested to always look for information about their condition through the media and help from health workers, and to maintain their nutritional status and cholesterol which is a source of estrogen that can affect their sexual satisfaction.

\section{Reference}

1. Pranoto. Masa Menopause Wanita. Yogyakarta: Universitas Gajah Mada; 2007.

2. Proverawati A, Sulistyawati E. Menopause dan Sindrom Premenopause. 2 ed. Yogyakarta: Nuha Medika; 2017.

3. Bara-baraya Health Center Makassar. Bara-baraya Health Center Makassar; 2015.

4. Marethiafani F, et al. Perimenopause Syndrome in Progesterone, Combination, and Non hormonal Contraceptive Acceptor. Muhammadiyah Medical Journal. 2015;1(2):26-31.

5. Nurningsih. Relationship between Knowledge Level about Menopause and Female Complaints at Menopause in Cijantung Sub-District, Kec. Pasar Rebo, East Jakarta in 2012 [Thesis]. [Jakarta]: Faculty of Medicine and Health Sciences Syarif Hidayatullah State Islamic University; 2012.

6. Population Office of Makassar City. 2015.

7. Lee Y, Lim M, Joo J, Park K, Lee S, Seo S, dkk. Development and validation of the Korean version of the Female Sexual Function Index-6 (FSFI-6K). Yonsei Med J. 2014;55(5):1442-6.

8. Idapola JS. The Relationship of Body Mass Index with Blood Biochemical Condition in PT Asuransi Jiwa Bumi Asih Jaya Employes. [Fakultas Kesehatan Masyarakat]: Universitas Indonesia; 2009.

9. Ali R, Hajeri R, Khader Y, Shegem N, Ajlouni K. Sexual Dysfunction in Jordanian Diabetic Women. Diabetes Care. 2008;31:1580-1.

10. Jacobsen SE. The Worldwide Potential of Quinoa (Chenopodium quinoa Willd.). Food Rev. 2003;19:167-77. 